\title{
A QUEM TUDO QUER SABER, NADA SE LHE DIZ: UMA EDUCAÇÃO SEM GÊNERO E SEM SEXUALIDADE É DESEJÁVEL?
}

\author{
Fernando Seffner ${ }^{1}$ \\ Yara de Paula Picchetti ${ }^{2}$
}

\section{Resumo}

As questões de gênero e sexualidade oscilam, há alguns anos, entre propostas explícitas de abordagem na escola, como foi o caso do tema transversal Orientação Sexual no interior dos Parâmetros Curriculares Nacionais, e sua negação, como recentemente foi a polêmica sob o rótulo de "ideologia de gênero", quando muitos municípios e estados retiraram de seus planos de educação a menção a gênero e sexualidade. Há claramente uma disputa política no interior da sociedade brasileira entre grupos que não desejam sua abordagem pela escola e outros que defendem com ardor que esses temas sejam ensinados de modo explícito. A partir da etnografia de cenas escolares, o texto evidencia que as salas de aula são locais altamente generificados, atravessados por questões de sexualidade e que a abordagem desses temas atende tanto à alfabetização científica quanto a numerosos outros propósitos em educação, que dizem respeito à preparação para a vida no espaço público de corte republicano.

Palavras-chave: Escola; Educação; Gênero; Sexualidade; Brasil

\footnotetext{
${ }^{1}$ Doutor em Educação. Endereço: Avenida Paulo Gama, Prédio 12201 Faculdade de Educação, sala 903, Campus Central da UFRGS, Porto Alegre, RS, Brasil, CEP 90046-900, Endereço eletrônico: fernando.seffner@ufrgs.br

${ }^{2}$ Mestre em Educação. Endereço: Avenida Paulo Gama, Prédio 12201 Faculdade de Educação, sala 903, Campus Central da UFRGS, Porto Alegre, RS, Brasil, CEP 90046-900, Endereço eletrônico: picohria@ yahoo.com.br
} 
SEFFNER, F.; PICCHETTI, Y. P.

\section{O NOVO POR NÃO SABER E O VELHO POR NÃO QUERER DEITAM TUDO A PERDER}

Escola é lugar de alfabetização científica, de aprender sobre o mundo e de preparar-se para a vida a partir de um currículo estabelecido, profissionais reconhecidos, disciplinas e projetos, calendário anual e seriação progressiva, acesso à biblioteca e a acervos, estratégias de avaliação das aprendizagens, convívio com colegas da mesma geração, encontros e trocas entre as culturas juvenis e brincadeiras e rituais de passagem. Escola é lugar de fazer perguntas e ter as perguntas respondidas em um clima de liberdade para ampliar os saberes. A escola oferta conhecimentos e busca interessar alunos e alunas no seu aprendizado através de uma diversidade de estratégias pedagógicas, configurando o que se costuma chamar de cultura escolar. Por cultura escolar entendemos um conjunto articulado de registros simbólicos, dispositivos disciplinares específicos, estrutura curricular, modos e meios de realizar as atividades, linguajar próprio, formas de avaliação e estratégias de sociabilidade e de socialização que permitem reconhecer os contornos da instituição, conhecer seus limites e possibilidades e pensar seu lugar e funções no tecido social e político. Outra característica importante do território escolar está assinalada por Delors (1994), quando afirma que os temas trazidos para estudo na escola devem estar em sintonia com os quatro pilares básicos da educação para o século XXI: aprender a ser, aprender a conhecer, aprender a conviver juntos e aprender a fazer ${ }^{3}$. A escola não abre mão de seu papel tradicional de alfabetização científica, mas agrega novas competências em conexão com a vida em sociedade e com a política como construção do bem comum.

Algo deve estar equivocado quando há propostas para retirada de temas, conhecimentos e oportunidades de convivência na escola sob a alegação de que ali não seriam bem-vindos. Em termos mais claros, há visível desconforto quando a escola se recusa a ensinar, comprometida com a produção da ignorância e não com a oferta de instâncias de aprendizado e convivência adequadas a cada faixa etária e contexto cultural. Defrontamo-nos com a situação em que as novas gerações desejam saber, mas as velhas gerações não querem abrir a possibilidade do aprender. As questões de gênero e sexualidade há alguns anos variam entre propostas explícitas de abordagem escolar, como foi o caso do tema transversal Orientação Sexual no interior dos

\footnotetext{
${ }^{3}$ Mais informações sobre essas proposições para a educação do século XXI podem ser obtidas junto ao Notre Europe Jacques Delors Institute: <http://www.delorsinstitute.eu/>. Acesso em: dez. 2014. 
Parâmetros Curriculares Nacionais (BRASIL, 1997), já previstos no Plano Decenal de Educação 1993-2003 (FARIA et al., 1999), e sua negação, como recentemente foi a polêmica sob o rótulo de "ideologia de gênero", quando muitos municípios e estados retiraram de seus planos de educação a menção ao aprendizado de questões de gênero e sexualidade ${ }^{4}$. Há claramente uma disputa política no âmago da sociedade brasileira entre grupos que não desejam sua abordagem pela escola (ROSADO-NUNES, 2015) e outros que defendem com ardor que esses temas sejam ensinados de modo explícito (BENTO, 2015).

Essa situação se prolonga já por vários anos, em especial após a promulgação da Constituição de 1988 e da Lei de Diretrizes e Bases da Educação Nacional, em 1996. Frente a isso, o propósito deste texto é simples. Por um lado, ele argumenta em favor de que a escola é local adequado para a abordagem de temas de gênero e sexualidade numa perspectiva biológica, mas também histórica, cultural e política, entendendo que gênero e sexualidade são marcadores que bem representam a estruturação e hierarquias das sociedades. Por outro lado, ele pretende mostrar que a escola e as salas de aula são territórios altamente generificados, nos quais o marcador de gênero opera o tempo todo, além de serem lugares em que as questões de sexualidade estão presentes, construindo posições de sujeito diversas:

\begin{abstract}
$\mathrm{Na}$ discussão que se segue estaremos muito preocupados com o uso e o sentido dos termos. [...] 'Sexo' será usado [...] como um termo descritivo para as diferenças anatômicas básicas, internas e externas ao corpo, que vemos como diferenciando homens e mulheres. Embora essas distinções anatômicas sejam geralmente dadas no nascimento, os significados a elas associados são altamente históricos e sociais. Para descrever a diferenciação social entre homens e mulheres, usarei o termo 'gênero'. Usarei o termo 'sexualidade' como uma descrição geral para a série de crenças, comportamentos, relações e identidades socialmente construídas e historicamente modeladas que se relacionam com o que Michel Foucault denominou 'o corpo e seus prazeres'. (WEEKS, 1999, p. 43, grifo do autor).
\end{abstract}

Dito de modo direto, este texto busca evidenciar que gênero e sexualidade são tanto elementos atuantes no território escolar como temas necessários para a aprendizagem das novas gerações. Para levar a cabo esses objetivos, o texto se serve da etnografia de cenas escolares,

\footnotetext{
${ }^{4}$ A polêmica mereceu ampla cobertura jornalística. Para conhecer um mapa da situação ao final do período de aprovação dos planos de educação (estaduais e municipais), veja: <http://www1.folha.uol.com.br/educacao/2015/06/1647528-por-pressao-planos-de-educacao-de-8-estados-excluemideologia-de-genero.shtml>. Acesso em: dez. 2015.
} 
derivadas do projeto de pesquisa intitulado "Ensino religioso no interior do estado laico: análise e reflexões a partir das escolas públicas de Porto Alegre"5. Ao analisar conteúdos, objetivos e fins do ensino religioso em um conjunto de escolas, nos deparamos com uma predominância absoluta da noção de "valores" estruturando o currículo desta disciplina, em formulações do tipo "cabe ao ensino religioso o ensino de valores". Dentre os valores listados como conteúdo do ensino religioso, as questões de gênero e sexualidade se mostraram muito frequentes (SEFFNER \& SANTOS, 2012). Isso nos levou a perseguir o tema, tanto com entrevistas a professores e alunos como na observação direta de aulas de ensino religioso, em que os temas de gênero e sexualidade eram abordados. Uma circulação mais ampla pelo território escolar nos permitiu flagrar situações em que questões de gênero e sexualidade estavam atuando em sintonia com outros marcadores da diferença, como geração, raça ou cor da pele, deficiência, pertencimento religioso, estrutura e composição familiar, origem regional e inserção na vida política. A escolha das aulas de ensino religioso para a coleta de dados acerca de gênero e sexualidade estava em sintonia com a disputa entre o campo religioso e o campo científico (em especial da saúde reprodutiva e sexual) nesse tema, oportunizando a compreensão dos mecanismos que podem, ou não, levar à construção de uma educação laica. Tal afirmação se ancora na importância que concedemos à noção de estado laico, fruto da percepção de que a escola é um espaço público, que não pode atender a demanda específica desta ou daquela religião, uma vez que atende a um público escolar diverso, e que não cabe ao estado promover uma determinada religião ou visão religiosa em detrimento de outras.

Os espaços em que vivemos são todos altamente generificados e com a constante presença de questões que evidenciam elementos da sexualidade nas trocas simbólicas. As relações que se produzem entre os indivíduos são atravessadas não apenas pelo marcador gênero (sou homem, sou mulher, isso é coisa de homem, isso é coisa de mulher), mas também pela sexualidade (o que aceito e o que não aceito em termos de sexualidade, como me defino e como defino os demais

\footnotetext{
5 Projeto de pesquisa vigente entre 2008 e 2013 que visava analisar as estratégias educacionais e os conteúdos presentes nas aulas de ensino religioso num conjunto de escolas públicas estaduais do município de Porto Alegre. O campo de trabalho em Porto Alegre foi coordenado por Fernando Seffner, e o projeto fazia interlocução com iniciativa mais ampla de pesquisa, coordenada pela Profa. Dra. Roseli Fischmann, da Faculdade de Educação da USP, em projeto intitulado "Ensino Religioso em Escolas Públicas: ameaças ao Estado laico e aos direitos sexuais e reprodutivos". No desenvolvimento deste segundo projeto o foco de pesquisa recaiu inteiramente nas situações de gênero e sexualidade em diálogo com o ensino religioso. Mais informações sobre os projetos em: <http://lattes.cnpq.br/2541553433398672>. A observação continuada das aulas de ensino religioso revelou muitos momentos em que questões de gênero e, em particular, relativas à masculinidade eram a tônica do debate.
} 
A QUEM TUDO QUER SABER, NADA SE LHE DIZ: UMA EDUCAÇÃO SEM GÊNERO E SEM SEXUALIDADE É

DESEJÁVEL?

quanto à sexualidade); pela cor da pele (sou branco, sou negro, sou mulato, sou indígena, sou amarelo); pela geração (sou velho, sou jovem, sou adulto, sou criança); pelo pertencimento religioso (tenho ou não uma crença religiosa, sou adepto com maior ou menor fervor a ela, aceito ou não compartilhar os espaços com os que não são da minha crença); pela origem regional (sou nordestino, sou gaúcho, sou carioca, sou do interior, sou da cidade grande, sou da periferia, sou do centro, sou do asfalto, sou da favela); pelo padrão estético (sou gordo, magro, alto, baixo, bonito, feio, careca ou não); pela disposição corporal (tenho alguma deficiência, não tenho, ela é visível ou não); pela classe econômica (sou pobre, rico, classe média, emergente, nova classe média, remediado); pelo nível educacional (fiz faculdade, não fiz, só tenho ensino fundamental, sou analfabeto, sou doutor); e pelo gosto cultural musical (sou roqueiro, pagodeiro, do funk, do axé, só escuto música clássica, só MPB, disco dance). Enfim, a cada momento, e em cada ambiente, os marcadores sociais estão jogando seu papel, anunciando possibilidades e restrições, instaurando aproximações ou afastamentos e podendo produzir situações de grave desigualdade social e política, inclusive com restrição de direitos fundamentais, e até mesmo violência.

Para ficar apenas na escola, território que nos interessa, gênero e sexualidade ajudam a moldar as possibilidades de relação e dizem respeito a quase tudo o que ali acontece: por que alguns estudam mais que outros? Por que alguns trazem material para a aula e outros sempre esquecem? Por que as aulas de artes são as preferidas de alguns e detestadas por outros? Por que se organizam filas para o ingresso na sala de aula? Por que as canecas da merenda escolar são azul e rosa? Por que o livro de registro das indisciplinas costuma ter frequência maior de meninos em suas anotações? Por que os banheiros são como são? Por que se separam meninos de meninas nas aulas de educação física? Cada período histórico gera um vocabulário educacional próprio. $\mathrm{O}$ regime democrático que vige no Brasil nas últimas décadas produziu seu impacto na linguagem educacional, e isso se manifesta, em particular, na noção de inclusão. A valorização da diversidade é característica dos ambientes democráticos, nos quais temos a criação de muitas identidades culturais e a associação de indivíduos em grupos de pertencimento (gênero, sexualidade, raça, etnia, pertencimento religioso, estilo musical, pertencimento político, profissão, deficiência ou necessidades especiais, região, geração, nacionalidade etc.). O vocabulário educacional contemporâneo incorporou fortemente as noções de diversidade, inclusão, educação em direitos humanos e culturas juvenis, e essas categorias todas podem ser 
SEFFNER, F.; PICCHETTI, Y. P.

pensadas em conexão com gênero e sexualidade: oferecer oportunidades educacionais com equidade entre meninos e meninas; incluir, de modo respeitoso, quem manifesta orientação sexual diferente da norma na escola; oferecer boa condição de aprendizagem e ambiente de respeito para meninos e meninas independentemente dos modos que desejam viver os atributos de masculinidade e feminilidade; respeitar e dialogar com os elementos das culturas juvenis, como o gosto musical, sabendo que os elementos de gênero e sexualidade são altamente frequentes nelas; possibilitar que cada um seja chamado pelo nome social se assim desejar, etc. É tarefa da escola cuidar para que não se produzam situações de desigualdade e restrição de oportunidades de aprendizagem por conta dos marcadores de gênero e sexualidade e, ao fazer isso, a escola educa para a vida no espaço público, local onde o respeito pela diversidade - por vezes nomeado como tolerância - deve ser a regra.

No interior desse novo contexto educacional, marcado pela diversidade e pelas demandas de respeito e inclusão, o professor é tanto o indivíduo que domina o conhecimento e as estratégias de ensino de uma disciplina específica como quem atua na qualidade de adulto de referência (SEFFNER, 2016) para as questões que dizem respeito aos valores que norteiam a vida no espaço público republicano. O desafio maior está dado pelo conceito de modus vivendi, capacidade de construir acordos entre indivíduos e grupos cujas opiniões difiram. Questões de gênero e sexualidade são vinculadas a conhecimento científico, ou seja, saber sobre gênero e sexualidade do ponto de vista biológico, histórico, linguístico, cultural, artístico, literário, da geografia humana, dos padrões de adoecimento, da vida política. Elas também dizem respeito a saber viver em sociedade e no âmbito do espaço público de feitio republicano, negociando as diferenças de gênero e sexualidade. Vale lembrar que um atributo forte do espaço público é ser lugar de intensa negociação das diferenças e de aprendizado político daí decorrente, cuidando para evitar que a diferença oportunize a criação de situações de desigualdade ou injustiça, como ocorre em ambientes de racismo institucionalizado, machismo predominante, heterossexualidade compulsória, privilégios apenas para aqueles que são de certa etnia ou classe social. O espaço público não é uma extensão do ambiente privado da casa, e não se pode imaginar que ele seja regido por uma lógica doméstica. No ambiente da casa, podemos escolher companhias e definir modos de proceder, dentro, é claro, dos limites da lei. No espaço público, vamos cruzar com indivíduos que diferem de nós, e nós deles, em muitos atributos. Essa é uma marca importante da 
vida em sociedade. No Brasil, acostumamo-nos a dizer que a família é a base da sociedade. Nada mais equivocado, a base da sociedade é o espaço público, lugar de negociação e respeito pela diversidade, onde aprendemos a conviver com os diferentes ao mesmo tempo em que percebemos que nossos gostos e opiniões políticas podem ser muito diferentes daqueles de outros indivíduos. A qualidade de vida em uma sociedade se mede mais pelo respeito ao espaço público do que propriamente pelo modo como as famílias se organizam, e convém lembrar que temos também uma diversidade de estruturas familiares nos dias de hoje, em todas as sociedades.

Modus vivendi diz respeito ao conjunto de estratégias sociais de que lançamos mão para aprender a viver em meio a uma sociedade que é, a cada dia, mais diversa (SEFFNER, 2015). Não há como imaginar que, no futuro, vamos viver em sociedades em que todos teremos a mesma religião, professaremos os mesmos valores políticos, teremos todos a mesma opinião sobre os modos de educar os filhos, gostaremos todos do mesmo estilo musical e artístico. Pelo contrário, a vida em sociedade é cada vez mais marcada pela presença da diversidade, a exigir constantes acordos de convívio. E a escola é um espaço público; a educação é um bem público e, como tal, prepara os indivíduos, em termos de conhecimentos e modos de convivência, para a vida em sociedade. Gênero e sexualidade são atributos importantes nessas negociações, e não será por retirar esses termos dos planos de educação que essas questões vão desaparecer das salas de aula. Os jovens vivem boa parte de sua vida social e de sua cultura juvenil na escola, tanto porque, a partir da Constituição de 1988, o ensino fundamental se tornou obrigatório quanto porque assistimos a uma extensão progressiva da escola de turno integral, em que os alunos ingressam pela manhã, saem ao final da tarde e ainda retornam aos fins de semana para atividades esportivas. E devem fazer tudo isso num ambiente de preparação para a vida no espaço público, norteada por valores republicanos. A escola precisa rever seus regulamentos e modos de funcionamento para não beneficiar apenas àqueles tradicionalmente representantes da hegemonia. Nas questões de gênero e sexualidade, a norma atende pelo nome de heteronormatividade. Mas as escolas não são lugares onde apenas habitam meninos e meninas heterossexuais. E, mesmo estes, não têm todos os mesmos modos de viver sua masculinidade ou feminilidade. 
SEFFNER, F.; PICCHETTI, Y. P.

As cenas que apresentamos a seguir privilegiam observação de comportamentos dos meninos $^{6}$. Os estudos sobre masculinidades ingressam com vigor no território da educação nos últimos anos, e no ambiente escolar em particular, e buscam mostrar as diferenças nas trajetórias de aprendizado entre meninos e meninas, a configuração da escola como um ambiente de viés feminino e as implicações disso para a construção das masculinidades entre os rapazes, as diferenças entre meninos e meninas no quesito desempenho escolar e no quesito disciplina e como esses dois atributos se embaralham (DAL'IGNA, 2005). Os estudos também observam a relação dos gêneros com a produção da cultura escolar, as conexões entre o desempenho escolar e o acesso ao mercado de trabalho, as tensões entre ser um bom aluno e produzir-se como um homem, a ênfase na interseccionalidade - considerando as diferenças nas trajetórias de meninos a depender da cor da pele, da classe social, da localização regional, do padrão estético, da orientação sexual, do pertencimento religioso - e as múltiplas influências recíprocas entre esses marcadores (ARTES; CARVALHO, 2010; CARVALHO, 2009; 2012; GONÇALVES; FRAGA, 2005; PEREIRA; CARVALHO, 2009; REZENDE; CARVALHO, 2012; SILVA, 2012). Em sintonia com a pesquisa acadêmica, mas guardando ritmo e velocidade próprios, os sistemas de ensino e muitos professores, de modo individual, envolvem-se em iniciativas que visam trazer questões de gênero e sexualidade para o debate e para o interior das propostas pedagógicas, dos regimentos escolares, das marcas da cultura escolar e do respeito com as culturas juvenis. Isso se verifica no campo da educação sexual, no regramento do uso do nome social e na ênfase numa educação que trabalhe com a equidade de gênero; enfim, com a proposição e o respeito pelas novas trajetórias de vida de meninos e meninas. Tudo isso, como é bem perceptível, mesmo a um olhar desatento no Brasil, tem produzido atritos com alguns setores sociais, em particular com os grupos religiosos.

Tomamos aqui diferenças de gênero e, em nosso foco, a produção de masculinidades como algo "não natural", um processo em aberto, atravessado por muitas vicissitudes, que podem produzir resultados diversos. Recusamos a ideia de que há uma correspondência essencial entre nascer macho e ser homem:

\footnotetext{
6 Tal situação deriva da inserção dos autores junto ao Programa de Pós-Graduação em Educação (PPGEDU) da UFRGS na linha de pesquisa Educação, Sexualidade e Relações de Gênero, com ênfase temática nas pedagogias de construção das masculinidades. Todos os nomes citados são fictícios para a preservação do anonimato dos envolvidos.
} 


\begin{abstract}
A dicotomia masculino-feminino (no sentido de macho e fêmea) é uma metáfora potente para a criação de diferença [...]. Não é, em si mesma, nem mais nem menos essencialista do que qualquer outro princípio de distinção, se aceitarmos que tanto o corpo sexuado como o indivíduo com gênero são resultados de processos de construção histórica e cultural. A compactação entre 'macho', 'homens' e 'masculinidade' [...] não deve ser tomada como certa, mas sim analisada. [...] (ALMEIDA, 1995, p. 161-162).
\end{abstract}

Analisamos os processos presentes nas cenas coletadas no ambiente escolar como processos que não seguem rotas lineares ou preestabelecidas. As negociações de gênero ali existentes podem apresentar vários desfechos, e situamos sua maioria no impasse entre ser bom aluno e produzir-se homem, na tensão entre atender expectativas sociais tradicionais e inovar em termos de significados de virilidade, na disputa de espaços com as meninas, na necessidade de marcar posição frente ao grupo de meninos. Reconhecemos também a presença de outras tensões na construção das masculinidades na escola, em particular intensas negociações para evitar a proximidade com o feminino ou com o homoerótico. Trabalhamos com a ideia de que os meninos e rapazes buscam um reconhecimento por seus pares na escola e que esse reconhecimento enfrenta tensões no eixo ser bom aluno e ser homem. Daí deriva outra constatação teórica: ninguém é exatamente homem "a priori”; essas definições sempre se dão no interior de um quadro de relações sociais e dependem de complexas negociações com outros elementos presentes no contexto. Modificando-se o contexto, os modos de buscar reconhecimento como homem se modificam também. Todo esse dinamismo social, envolvendo gênero e sexualidade, não pode deixar de ser objeto explícito da atenção do sistema educacional.

\title{
2 CADA UM VÊ MAL OU BEM CONFORME OS OLHOS QUE TEM
}

Passamos agora a descrever e comentar as cenas etnografadas em escolas. Adotamos a estratégia de uma descrição densa, que já contempla a análise. Ela é fruto de um duplo trabalho sobre as cenas: anotação inicial, feita no próprio momento em que a cena se desenrolava, e discussão posterior da cena no grupo de pesquisa, enriquecendo a descrição com categorias de análise e pontos de vista de outros pesquisadores ou da bibliografia. A coleta das cenas foi feita com os pesquisadores presentes na sala de aula, sentados ao fundo, e tendo eles explicado à 
SEFFNER, F.; PICCHETTI, Y. P.

classe de alunos os motivos de sua presença, após entendimentos com a direção da escola e com os professores, e com termo de consentimento informado assinado. Longe de constranger os alunos, a presença dos pesquisadores parece ter funcionado na direção oposta, ou seja, estimulou debates e enfrentamentos, uma vez que havia observadores externos, aos quais cumpria “impressionar". Ao final de algumas aulas, alguns alunos procuraram os pesquisadores para narrar, de modo espontâneo, enfrentamentos em temas de gênero e sexualidade que lhes pareciam importantes, e que já haviam sido palco na escola. Todas as cenas etnografadas insistem na ideia de que os temas de gênero e sexualidade são contingentes, urgentes, presentes e atuantes no espaço escolar, a pedir intervenção pedagógica adequada e sensível. Assumimos que as salas de aula são contextos generificados e sexualizados e que as relações entre os alunos e alunas e destes com os docentes são atravessadas pelos marcadores de gênero e sexualidade. Portanto, posturas que insistem no adiamento desses debates estão em desacordo com a contingência que se observa no dia a dia das salas de aula. Por outro lado, busca-se mostrar, na análise das cenas, que não é apenas porque as questões de gênero e sexualidade já estão constituindo o espaço escolar que elas devem ser discutidas, ou seja, não é simplesmente porque elas já estão lá que se deve atentar para

elas e conduzir abordagens adequadas. É, também, porque elas estão conectadas com a educação em direitos humanos e com o aprendizado das normas que devem reger a vida no espaço público, em particular a noção de modus vivendi, conforme demonstrado. Há que se ter olhos para isso e sensibilidade para encaminhar estratégias educativas nesses temas.

\subsection{Quem pode fazer o quê?}

Classe bastante numerosa de alunos do nono ano do ensino fundamental, turno da tarde. $\mathrm{O}$ professor de ensino religioso parece ter uma ótima relação com a classe, todos gostam dele, fazem brincadeiras e ajudam na manutenção da disciplina, o que, em parte, acontece porque estamos observando, e somos da universidade, o que foi deixado claro aos alunos pelo professor. A atividade proposta por ele, coerente com a etapa final do ensino fundamental, que é o nono ano, foi a produção de um curto texto pessoal sobre as expectativas profissionais de cada um para posterior debate no grupo. Decorrido o tempo das escritas individuais, o professor organizou uma tabela no quadro, em que ia colocando as profissões desejadas por meninos e meninas, seguidas 
de algumas argumentações e comentários. Logo ficou claro que as meninas apresentaram um leque maior de opções do que os meninos. Ao lado de profissões tipicamente femininas, como enfermeira, professora, nutricionista, as meninas citaram engenharia, química, advocacia e inovaram com profissões como motorista de táxi, piloto de avião, gerente de fábrica. Os meninos colocaram profissões masculinas tradicionais, incluindo jogador de futebol, com destaque.

O professor, bastante atilado, salientou que a lista das meninas era mais variada em termos de opções. As meninas se apressaram em fazer duas afirmativas claras: as mulheres, hoje em dia, podiam exercer todas as profissões dos homens, pois elas tinham capacidade, eram muito estudiosas e iam bem na escola. Os meninos reagiram dizendo que eles não precisavam estudar, com frases como "eu sou inteligente; na hora do exame vestibular, eu vou lá e acerto tudo". As meninas duvidaram, e o professor, que revelou estar bem informado das estatísticas, disse que, nos últimos anos, as meninas eram mais numerosas no ingresso ao ensino superior do que os meninos. A discussão então ficou em torno de que era necessário estudar para ter acesso a boas profissões. Mas os meninos insistiam em dizer que eles poderiam ter acesso a boas profissões sem estudar, e um deles deu o conhecido exemplo, que é muito visível em supermercados: as meninas trabalham como funcionárias das caixas registradoras, mas todos os fiscais de caixa são homens, então os homens mandam nas mulheres no ambiente de trabalho, disse ele, o que acendeu a polêmica. Claramente havia uma recusa por parte dos meninos em aceitar a premissa de que era necessário estudar para ter garantia de um bom emprego, e insistiam na tese de que eles poderiam ter acesso a bons empregos sem estudar. Ficou bastante evidente que o caminho proposto "estudar e ser um bom aluno para então ter sucesso na vida profissional" era visto como um caminho feminino, por conta do apego aos estudos. Eles então deram exemplos de jogadores de futebol, de apresentadores de programas jovens na televisão, de cantores, atletas em geral, vereadores e deputados, inventores na área da informática e até mesmo de traficantes de drogas, dos quais se diz que possuíam algum talento e obtiveram sucesso profissional sem necessidade de estudar. O talento foi tomado como algo masculino, algo que "estava" na pessoa e que the asseguraria sucesso profissional. Um menino foi claramente motivo de troça pelas meninas, pois ele afirmou que seria um grande engenheiro de transportes, e elas disseram que ele não estudava nada, ao que ele respondeu "quando eu precisar, eu vou estudar e vou passar no exame vestibular, 
SEFFNER, F.; PICCHETTI, Y. P.

pois eu sei que sou inteligente. Agora não vale a pena estudar ainda; essa escola aqui é muito podre".

A noção de uma inteligência nata, com a qual os homens nascem, associada a certo desembaraço, também visto como natural na esfera pública, ficou evidente na argumentação. Outra fonte de discórdia aconteceu porque uma menina disse claramente que "as mulheres estavam tomando conta dos empregos dos homens, mas os homens não tinham coragem de exercer os empregos das mulheres, como cabeleireiro, e então as mulheres tinham cada vez mais oportunidades". Os meninos reagiram prontamente, dizendo que eles não iam ser cabeleireiros, manicures, telefonistas, mesmo que isso trouxesse bons salários. As meninas então insistiram em dizer que, se as coisas iam assim, as mulheres cada vez mais teriam bons empregos, o que foi difícil de contestar pelos meninos. Por coincidência, na mesma quadra da avenida onde funciona a escola, há dois grandes salões de beleza, nos quais os profissionais são mulheres e homens gays, e isso entrou na discussão. As meninas disseram que as mulheres donas dos salões eram "ricas" - citaram, inclusive, seus nomes e a marca dos carros que elas possuíam - e que os gays, que eram cabeleireiros, também eram "ricos" e possuíam carro melhor do que os carros dos professores, o que provocou risadas gerais, mas sem constrangimento do professor, que acompanhou tudo de forma bem humorada. Com isso, as meninas encurralaram os meninos, mas estes insistiram em dizer que "era só o que faltava serem cabeleireiros de salão", o que só foi admitido, em tom de troça, quando um dos meninos disse "eu só trabalho em salão se for para fazer massagem nas mulheres". Aqui se revelou uma conhecida estratégia dos meninos em muitos debates, que é introduzir elementos de deboche e ironia e, com isso, inviabilizar uma reflexão mais profunda em torno das diferenças de gênero e oportunidades profissionais. De todo modo, foi visível que a atividade produziu certo desassossego nos modos tradicionais como os meninos equacionam a vida profissional futura.

\subsection{Desempenho escolar não tem gênero?}

Uma classe de oitavo ano do ensino fundamental, sala repleta, alunos e alunas em torno de 12 e 13 anos, turno da manhã. A professora de ensino religioso é também professora de literatura da classe. Ao final da aula, ela aproveita para devolver as provas de literatura após ter 
feito comentários sobre as notas. Ela havia ordenado as provas de acordo com as notas, então aqueles que foram chamados inicialmente haviam recebido as melhores notas. São entregues oito provas para meninas quando, então, ela chama o primeiro menino. Assim que ele se levanta para buscar sua prova, vários outros meninos começam a fazer troça, dizendo frases como "mais uma menina que tirou boas notas na prova de literatura" e "uiii, menina estudiosa". Ao pegar a prova, ele volta para seu lugar, dizendo em alto e bom som "eu nem estudei nada, eu colei tudo; obrigado, Rosane", e todos riem. Quando ele senta, percebemos que a menina na carteira ao seu lado é a Rosane, que foi chamada em primeiro lugar, tendo, portanto, tirado a melhor nota. Claramente era uma disputa em termos de representações de masculinidade, e o aluno em questão precisava defender-se da suspeita de que, tendo obtido uma boa nota na prova de literatura, ele talvez não fosse tão masculino quanto se poderia esperar. Tal preocupação não foi observada entre as meninas que tiraram boas notas, que foram inclusive cumprimentadas pelas colegas.

\subsection{Comportado, atento, participativo, estudioso: é possível ser assim e ser menino?}

Entrei na sala ${ }^{7}$, apresentei-me à turma e fui sentar no fundo da sala, como de costume. Uma turma de ensino médio com 12 meninas e 11 meninos. As carteiras estão organizadas em três filas duplas. O único menino - Alfredo - que está sentado ao lado de uma menina é claramente mais delicado que os demais e veste-se também de um modo que poderíamos classificar como mais original e detalhado do que os demais meninos - todos eles de bermuda, camiseta e tênis. Já antes de entrar na aula, ele estava no corredor, em meio a um grupo de meninas, enquanto os garotos estavam todos juntos fazendo algazarra. Esse menino ocupa a primeira carteira próxima à porta. Há uma menina ao seu lado e outra atrás; mais para trás na fileira, há apenas meninas. Todos os demais meninos estão sentados em duplas, prioritariamente na fileira rente às janelas, oposta à porta, ou no fundo da sala. Nas fileiras centrais, há algumas meninas em dupla, mas é uma área mais rarefeita da sala, com poucos alunos. Topograficamente falando, temos uma divisão clara na turma entre meninos e meninas. Alfredo está segregado dos demais meninos, mas integrado na turma das meninas. Mais ainda, ele se revelou na aula ser

\footnotetext{
${ }^{7}$ Essa cena foi etnografada apenas pelo autor principal.

Revista Reflexão e Ação, Santa Cruz do Sul, v. 24, n. 1, p. 61-81, Jan./Abr. 2016.

http://online.unisc.br/seer/index.php/reflex/index
} 
SEFFNER, F.; PICCHETTI, Y. P.

muito participativo e foi acompanhado nas falas por várias meninas. Ele é extremamente simpático e bem-humorado e manteve, em vários momentos, um diálogo com a professora, articulando questões bem-formuladas sobre o tema da aula, no que igualmente foi acompanhado por algumas meninas. É bastante visível que ele é o menos infantil dos meninos em seu vocabulário, postura e falas. Os demais meninos estiveram apáticos quase toda a aula, embora não tenham feito bagunça ou algazarra, mas apenas um deles abriu o caderno; os demais sequer abriram a mochila, o que também aconteceu por conta dos procedimentos didáticos da professora, que ficou discutindo questões e em momento algum solicitou que anotassem algo. Mas as meninas e o Alfredo, estes, sim, abriram os cadernos e anotaram algumas coisas. Ou seja, acompanhando a divisão de gênero, havia uma divisão igual em termos de envolvimento nos estudos. A atmosfera que era possível respirar na aula poderia ser assim definida: estudar e conversar com a professora é coisa de meninas; os meninos ficam ali por uma espécie de obrigação. Sendo o estudo uma coisa de meninas, o menino que estuda é claramente localizado no campo do feminino pelos demais meninos. Quando o sinal tocou, eles simplesmente voaram porta afora para fazer zoada no corredor. As meninas e o Alfredo ficaram na sala de aula, já arrumando as classes para o período seguinte, que entendi que seria o da aula de artes, e a professora queria que fizessem grupos de quatro pessoas para seguir analisando gravuras, tarefa já iniciada em período anterior.

\subsection{Mulher é sexo}

Ao identificar-me na escola ${ }^{8}$ e dizer dos meus interesses em observar as aulas de ensino religioso para, em especial, perceber se temas de gênero e sexualidade eram abordados por alunos e docentes, fui cercado por três professoras, desejosas de contar-me um episódio que as havia perturbado singularmente. A escola é de ensino fundamental completo e costuma receber, na quinta série, alunos transferidos de outras duas escolas próximas, que apenas trabalham com as séries iniciais. Dessa forma, já é tradicional que se organize, na primeira semana, um evento em que os alunos que já estudam na escola e os novos alunos que nela estão ingressando participem

\footnotetext{
${ }^{8}$ Essa cena foi etnografada apenas pelo autor principal. 
de atividades de integração. Essa atividade é realizada com todas as turmas de quinta série e, ao longo dos anos, foram praticados diversos tipos de jogos e brincadeiras para dar conta da desejada integração. Professores e professoras também participam dessa atividade, apresentandose para as turmas e dizendo algo sobre o ensino das suas disciplinas específicas.

Naquele ano, a atividade principal de integração havia sido solicitar às meninas que se fantasiassem de meninos, e aos meninos que se fantasiassem de meninas, e que cada um comentasse um pouco sobre a fantasia escolhida, o que se pretendia ser um modo divertido de os meninos elogiarem as meninas, e as meninas elogiarem os meninos, dando-se a conhecer e experimentando o lugar do outro. Para tanto, foram reunidos, em uma sala, os meninos e, em outra, as meninas; em cada uma das salas havia abundante vestuário e outros adereços para que se produzissem as fantasias. As meninas levaram roupas de meninas, e os meninos levaram roupas de meninos e, na hora, essas roupas foram trocadas para que cada grupo se fantasiasse. Além do que foi levado, a própria escola contava com muitas fantasias para as atividades de teatro que foram mobilizadas nesse momento. Os professores e as professoras também se dividiram: professores homens ficaram na sala dos meninos (havia apenas dois professores homens), e as professoras ficaram na sala das meninas. Professores e professoras também se fantasiaram com as vestimentas do sexo oposto.

Decorrido um tempo suficiente para que se fantasiassem, foi dado um sinal, e todos saíram para o pátio, foram dispostos em duas linhas, frente a frente, para observar-se, para comentar o que lhes parecia adequado sobre a fantasia feita e para dar conta do objetivo de diversão e integração da atividade. Nesse momento da narrativa, as três professoras demonstraram o quanto haviam ficado incomodadas, pois todas falavam ao mesmo tempo. Ocorre que as meninas e as professoras fizeram a atividade do modo que elas denominaram como “correto", “adequado", "sem malícia", "para se divertir", "para brincar", "respeitoso", "como tem que ser na escola". Ou seja, as meninas se vestiram como garoto de futebol e segurando uma bola; como motorista de ônibus com quepe e segurando um volante; como médico com uniforme branco; como juiz com uma toga; como pedreiro com uma colher de argamassa na mão; como professor com giz e apagador na mão; como dançarino de hip-hop com bermudas e adereços de couro; como um técnico "nerd" em computação com um monte de fios nas mãos; como um 
SEFFNER, F.; PICCHETTI, Y. P.

garoto bem ajeitadinho com cabelo moicano; como um policial com revólver na mão; etc. Uma das professoras se fantasiou de padre; outra, de juiz de futebol, dentre outras escolhas.

Já os garotos se vestiram de enfermeira, psicóloga, nutricionista, caixa de supermercado, cozinheira, freira, telefonista, modelo e manequim, vendedora de loja, professora, executiva de negócios, caixa de banco, apresentadora de televisão, havia até mesmo um garoto vestido de presidenta da república, com uma faixa. A questão é que a maior parte das fantasias apresentava um apelo sexual evidente e forçado, e isso incluiu até mesmo os professores, um dos quais estava fantasiado de aeromoça, com requebros sensuais, vestido muito curto e blusa decotada. Mais ainda, os meninos todos caminhavam e falavam com evidente apelo erótico: rebolando, dizendo coisas com segundo sentido, passando a mão na região dos seios, deixando à mostra as pernas, forçando posições de oferecimento sexual. E isso sem contar o exagero no uso da maquiagem, que foi comum a praticamente todas as fantasias. Segundo as professoras, poucos meninos não abusaram dessa estratégia, e estes poucos se sentiam até mesmo desconfortáveis no meio dos demais.

A professora que estava contando o episódio de maneira mais exaltada explicitou o desfecho da atividade: ela havia ficado tão injuriada com aquilo, e muito por conta da cumplicidade dos dois colegas professores, que, de modo intempestivo, passou a "bater boca" com os meninos, fazendo ver o quão ofensivo era aquele comportamento para com as meninas e mulheres presentes. Segundo as outras duas professoras, que inicialmente estavam mais tranquilas, mas logo concordaram com a colega, sobre aquilo ser um insulto, o assunto "ferveu", e a situação apenas não saiu do controle porque algumas professoras encerraram a atividade, dizendo que aquilo era algo para ser conversado depois, que o objetivo da atividade era integração e não zombaria e briga e que estava tudo errado - era melhor encerrar. As crianças foram liberadas para tirar as fantasias, devolver as roupas e ir para o recreio. Com isso, o assunto se encerrou, mas as feridas ficaram. As três professoras foram unânimes em dizer que, daquele dia em diante, estava difícil a relação com os meninos e, em especial, com os dois colegas professores que, segundo elas, deveriam ter impedido que os meninos tomassem o caminho que tomaram na produção das fantasias. Ao mexer com marcadores de gênero e sexualidade, as professoras não imaginaram que a situação fosse gerar todo esse desconforto e agora não sabiam bem como encaminhar uma reflexão. Esse episódio teve desdobramentos com a organização de 
A QUEM TUDO QUER SABER, NADA SE LHE DIZ: UMA EDUCAÇÃO SEM GÊNERO E SEM SEXUALIDADE É

DESEJÁVEL?

oficinas para conversar sobre o acontecido e com a assessoria de alunos já formados em nossos cursos de gênero e sexualidade, que aqui não constituem objeto da narrativa.

\section{VIVER NÃO CUSTA, O QUE CUSTA É SABER VIVER}

Uma sala de aula é um ambiente generificado e igualmente sexualizado. Ou seja, esses marcadores estão presentes e operando o tempo todo, conforme buscamos evidenciar nas cenas descritas. Muitas relações sociais se constroem no território escolar a partir de diferenças percebidas entre os gêneros e entre orientações sexuais, seja para aproximar ou afastar indivíduos. Todavia, a questão não é meramente de amizade ou não amizade. Há efetivamente uma distribuição de poder na sala de aula, que deriva dos atributos de gênero e sexualidade - bem como de cor da pele, classe econômica, padrão estético e outros elementos que aqui não temos como problematizar na interseccionalidade com o foco do texto. O que queremos ressaltar é que as diferenças de gênero que se percebem numa sala de aula, bem como as diferenças de sexualidade, operam no sentido de conceder a alguns mais poder do que a outros em certos contextos, suscetíveis de modificação ao sabor das intervenções de colegas, professores ou elementos emergentes do cotidiano social e cultural. Muitos dos enfrentamentos que acontecem em sala de aula - entre alunos e alunas, entre alunos, entre alunas, entre o alunado e o professorado, entre estes e as diretrizes educacionais - pode ser considerado como pertencente a pauta do gênero e da sexualidade. Sempre é bom lembrar a afirmação de Scott (1995, p. 86): “[...] o gênero é uma forma primária de dar significado às relações de poder”. Daí se conclui que, quando professores e professoras planejam abordagens de gênero e sexualidade na escola, não

devem limitar-se a identificar o que são códigos do feminino e do masculino ou mesmo a descrever apenas as diferentes orientações sexuais que existem. De modo muito mais profundo, essas questões estão inseridas no campo dos direitos humanos, ou seja, elas dizem respeito à vida política no espaço público e à distribuição de poder e de oportunidades entre pessoas.

Valorizar a diversidade e promover a igualdade articulam-se com o regime democrático e com o espaço público de corte republicano. Os esforços para convívio entre os diferentes, que aqui estamos chamando de modus vivendi, trazem movimento ao regime político e permitem a 
SEFFNER, F.; PICCHETTI, Y. P.

cada um o aprendizado sobre a importância da elaboração de regras sociais. Promover situações de justiça social, econômica e cultural, bem como situações de justiça com os marcadores de gênero e sexualidade, é certamente uma tarefa complexa, a exigir aprendizado desde os bancos escolares. Não se trata apenas de estabelecer o diálogo entre os diferentes, mas de modificar estruturas capazes de produzir desigualdade e injustiça nas questões de gênero e sexualidade. A educação é tarefa que tem óbvias implicações políticas, e a disputa sobre o ingresso ou não dos temas de gênero e sexualidade nos currículos reflete exatamente isso. As questões que envolvem disputas de gênero e sexualidade exigem enorme habilidade de conduta pedagógica e certamente devem fazer parte dos cursos de formação docente.

\title{
STUDENTS WANT TO KNOW, BUT TEACHERS CANNOT TEACH: IS AN EDUCATION WITH NO GENDER NOR SEXUALITY DESIRABLE?
}

\begin{abstract}
In Brazil, the relationship between gender and sexuality and school oscillates between two extremes. We have explicit proposals for school approach, as was the case of Sexual Orientation, an interdisciplinary theme within the National Curriculum Guidelines. We have rejection of its teaching, as was recently the controversy under the label of "gender ideology" when many municipalities and states withdrew from their education plans the discussion on gender and sexuality. There is clearly a political dispute within Brazilian society between groups which are against schools approaching it and others which argue passionately that these subjects must be taught explicitly. Based on the ethnography of school scenes, this text shows that classrooms are highly gendered spaces crossed by issues of sexuality. The approach to these themes serves the purpose of both scientific literacy and numerous other ones in education concerning how one should be prepared for life in the republican public space.
\end{abstract}

Keywords: School; Education; Gender; Sexuality; Brazil

Revista Reflexão e Ação, Santa Cruz do Sul, v. 24, n. 1, p. 61-81, Jan./Abr. 2016.

http://online.unisc.br/seer/index.php/reflex/index 


\section{TODOS QUIEREN SABER, PERO NADA SE LES DICE: UNA EDUCACIÓN SIN GÉNERO Y SIN SEXUALIDAD ES DESEABLE?}

\section{Resumen}

En Brasil, la relación entre el género y la sexualidad y la escuela oscila entre dos extremos. Tenemos propuestas explícitas para el enfoque de la escuela, como fue el caso del tema transversal Orientación Sexual dentro de las Directrices Curriculares Nacionales. Y tenemos procesos de negación de su enseñanza, como fue recientemente la controversia bajo la etiqueta de "ideología de género" cuando muchos municipios y estados retiraron de sus planes de educación la mención a género y sexualidad. Es evidente que hay una disputa política dentro de la sociedad brasileña entre los grupos que no desean su enfoque en la escuela y otros que defienden apasionadamente que estas materias se enseñan de manera explícita. De la etnografía de las escenas de la escuela el texto muestra que las aulas están muy atravesadas por el género y por temas de sexualidad. El enfoque de estos temas sirve tanto a la alfabetización científica como numerosos otros fines en la educación, en relación con la preparación para la vida en el espacio público de corte republicano.

Palabras clave: Escuela; Educación; Género; Sexualidad; Brasil

\section{REFERÊNCIAS}

ALMEIDA, Miguel Vale de. Senhores de Si: uma interpretação antropológica da masculinidade. Lisboa: Fim de Século, 1995.

ARTES, Amélia Cristina Abreu; CARVALHO, Marília Pinto de. O Trabalho como Fator Determinante da Defasagem Escolar dos Meninos no Brasil: mito ou realidade? Cadernos Pagu, Campinas: Universidade Estadual de Campinas; Campinas: Editora da Unicamp, n. 34, p. 41-74, jan./jun. 2010. 
SEFFNER, F.; PICCHETTI, Y. P.

BENTO, Berenice. Disputas de Gênero. Correio Braziliense, Brasília, 30 jun. 2015. Opinião, p. 11.

BRASIL. Secretaria de Educação Fundamental. Parâmetros Curriculares Nacionais: orientação sexual. Brasília: Ministério da Educação/Secretaria de Educação Fundamental, 1997.

CARVALHO, Marília Pinto de. Gênero, Raça e Avaliação Escolar: um estudo com alfabetizadoras. Cadernos de Pesquisa, São Paulo: Fundação Carlos Chagas; São Paulo: Fundação Carlos Chagas, v. 39, n. 138, p. 837-866, set./dez. 2009.

CARVALHO, Marília Pinto de. Teses e Dissertações sobre Gênero e Desempenho Escolar no Brasil (1993-2007): um estado da arte. Pro-Posições, Campinas: Universidade Estadual de Campinas; Campinas; Editora da Unicamp, v. 23, n. 1, p. 220-244, 2012.

DAL'IGNA, Maria Cláudia. "Há Diferença"?: relações entre desempenho escolar e gênero. 2005. 167f. Dissertação (Mestrado em Educação) - Universidade Federal do Rio Grande do Sul, Porto Alegre, 2005.

DELORS, Jacques. La Educación encierra un Tesoro: informe de la UNESCO de la comisión internacional para la educación para el siglo XXI. Madrid: Santillana/Ediciones UNESCO, 1994.

FARIA, Nalu et al. (Org.). Caderno Educação e Gênero. São Paulo: SempreViva Organização Feminista, 1999.

GONÇALVES, Vinícius Pauletti; FRAGA, Alex Branco. A Quadra e os Cantos: arquitetura de gêneros nas práticas corporais escolares. Lecturas: educación fisica y deportes, Buenos Aires: [s.n.]; Buenos Aires: [s.n.], v. 10, n. 87, ago. 2005.

PEREIRA, F. H.; CARVALHO, M. P. Meninos e Meninas num Projeto de Recuperação Paralela. Revista Brasileira de Estudos Pedagógicos, Brasília: Instituto Nacional de Estudos e Pesquisas Educacionais Anísio Teixeira; Brasília: Instituto Nacional de Estudos e Pesquisas Educacionais Anísio Teixeira, v. 90, n. 226, p. 673-694, 2009.

REZENDE, A. B.; CARVALHO, M. P.. Meninos Negros: múltiplas estratégias para lidar com o fracasso escolar. Sociologia da Educação: revista luso-brasileira, Rio de Janeiro: Pontifícia Universidade Católica do Rio de Janeiro; Rio de Janeiro: Pontifícia Universidade Católica do Rio de Janeiro, v. 3, n. 5, p. 59-89, out. 2012.

ROSADO-NUNES, Maria José Fontelas. A “Ideologia de Gênero” na Discussão do PNE: a intervenção da hierarquia católica. Horizonte, Belo Horizonte: Pontifícia Universidade Católica de Minas Gerais; Belo Horizonte: Pontifícia Universidade Católica de Minas Gerais, v. 13, n. 39, p. 1237-1260, jul./set. 2015.

SCOTT, Joan. Gênero: uma categoria útil de análise histórica. Revista Educação \& Realidade, v.20, n. ${ }^{\text {2 }}$, julho/dezembro de 1995, pp. 71-99 
SEFFNER, Fernando. Escola Pública e Professor como Adulto de Referência: indispensáveis em qualquer projeto de nação. Educação Unisinos, São Leopoldo: Universidade do Vale do Rio dos Sinos; São Leopoldo: Universidade do Vale do Rio dos Sinos, 2016. No prelo.

SEFFNER, Fernando. Modus Vivendi, Liberdade Religiosa e Liberdade Sexual: o que a escola tem a ver com isso? In: NARDI, Henrique Caetano et al. (Org.). Diversidade Sexual e Relações de Gênero nas Políticas Públicas: o que a laicidade tem a ver com isso? Porto Alegre: Editora Deriva/ Associação Brasileira de Psicologia Social, 2015. Pp.81-104

SEFFNER, \& SANTOS, Renan Bulsing. Ensino Religioso no interior do Estado Laico: análise e reflexões a partir do estudo de caso em três municípios gaúchos. Notandum (USP) São Paulo, v. 28, p. 67-80, 2012.

SILVA, Luciano Ferreira da. Mind the Gap: processos de construção e manutenção das masculinidades e distanciamentos no desempenho escolar de meninos e meninas. 2012. $178 \mathrm{f}$. Dissertação (Mestrado em Educação) - Universidade Federal do Rio Grande do Sul, Porto Alegre, 2012.

WEEKS, Jeffrey. O Corpo e a Sexualidade. In: LOURO, Guacira Lopes (Org.). O Corpo Educado: pedagogias da sexualidade. Belo Horizonte: Autêntica, 1999. Pp.35-82 